\title{
PARA BRILHAR NA SAPUCAÍ HIERARQUIA E LIMINARIDADE ENTRE AS ESCOLAS DE SAMBA
}

Ricardo José de Oliveira Barbieri

O artigo parte da análise da hierarquia competitiva em que estão inseridas as escolas de samba para tomá-las na atuação de suas redes de relações. Nesse processo observa-se o desenvolvimento de espaços de passagem não demarcados explicitamente na hierarquia. Diferenças significativas na estrutura de desfile e processos de preparação bem como aspectos organizacionais desenvolvidos ao longo dos anos são importantes em sua observação. [abstract on page 280]

ESCOLAS DE SAMBA, HIERARQUIA, COMPETIÇÃO, SOCIABILIDADE. 


\section{AS ESCOLAS DE SAMBA DO RIO DE JANEIRO E SUA ESTRUTURA RITUAL COMPETITIVA}

A importância do desfile das escolas de samba como processo ritual foi bem observado por Maria Laura Cavalcanti (2006), que retomou a tradição antropológica dos estudos de ritual desenvolvidos por Turner (1978) e DaMatta (1973). A competição festiva caracterizaria o desfile das escolas de samba na festa carnavalesca. $O$ desfile emerge como resultado de todo o ciclo anual de sua preparação, configurando um tempo próprio chamado pela autora de "ano carnavalesco" (CAVALCANTI, 2006, p. 39). Cada desfile é, então, o apogeu de um ciclo anual em que a "rede de relações sociais trançada ao longo do ano atinge seu grau máximo de expansão" (CAVALCANTI, 2006, p. 233). O desfile é também uma competição, um espaço de trocas agonísticas (MAUSS, 2001), em que, como mostrou Cavalcanti (2006), as escolas a um só tempo rivalizam e confraternizam. É essa capacidade de expandir a rede de relações sociais, trançada ao longo de cada ano, que nos leva, enfim, a entender de que forma os desfiles absorvem e irradiam os conflitos e as transformações pelos quais passa a cidade que os abriga. Esse aspecto denota a importância das escolas de samba para estudos de antropologia urbana na cidade do Rio de Janeiro e inspira a elaboração deste artigo.

Dessa forma pretendemos nos voltar para a explicação do funcionamento desse sistema ritual-competitivo como um todo e buscar compreender como as escolas circulam por tal sistema durante suas trajetórias de vida. Como são encaradas suas derrotas e vitórias dentro do sistema ritual-competitivo no qual estão imersas?

$\mathrm{Na}$ tentativa de mapear uma hierarquia competitiva das escolas de samba, apresentamos um quadro de referência a ser utilizado até o final deste artigo (Tabela 1).

\begin{tabular}{|c|c|c|c|c|c|c|}
\hline Grupo & Entidade & $\begin{array}{l}\text { Local de } \\
\text { desfile }\end{array}$ & $\begin{array}{l}\text { Dia de } \\
\text { desfile }\end{array}$ & $\begin{array}{l}\text { Partici- } \\
\text { pantes } \\
2010\end{array}$ & $\begin{array}{l}\text { Preparação dos } \\
\text { desfiles }\end{array}$ & $\begin{array}{l}\text { Classifica- } \\
\text { ção Neutra }\end{array}$ \\
\hline Grupo Especial & LIESA & Sambódromo & $\begin{array}{l}\text { Domingo/ } \\
\text { Segunda }\end{array}$ & 12 & Cidade do Samba & $\begin{array}{l}\text { Primeira } \\
\text { divisão }\end{array}$ \\
\hline $\begin{array}{l}\text { Grupo de } \\
\text { Acesso A }\end{array}$ & LESGA & Sambódromo & Sábado & 12 & 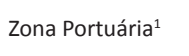 & $\begin{array}{l}\text { Segunda } \\
\text { divisão }\end{array}$ \\
\hline $\begin{array}{l}\text { Grupo Rio de } \\
\text { Janeiro } 1\end{array}$ & AESCRJ & Sambódromo & Terça & 12 & $\begin{array}{l}\text { Carandiru e Zona } \\
\text { Portuária }\end{array}$ & $\begin{array}{l}\text { Terceira } \\
\text { divisão }\end{array}$ \\
\hline $\begin{array}{l}\text { Grupo Rio de } \\
\text { Janeiro } 2\end{array}$ & AESCRJ & $\begin{array}{l}\text { Intendente } \\
\text { Magalhães }\end{array}$ & Domingo & 14 & Carandiru 1 e 2 & $\begin{array}{l}\text { Quarta } \\
\text { divisão }\end{array}$ \\
\hline $\begin{array}{l}\text { Grupo Rio de } \\
\text { Janeiro } 3\end{array}$ & AESCRJ & $\begin{array}{l}\text { Intendente } \\
\text { Magalhães }\end{array}$ & Segunda & 15 & $\begin{array}{l}\text { Carandiru } 1 \text { e } 2 \text { e } \\
\text { espaços próximos } \\
\text { das quadras }\end{array}$ & $\begin{array}{l}\text { Quinta } \\
\text { divisão }\end{array}$ \\
\hline $\begin{array}{l}\text { Grupo Rio de } \\
\text { Janeiro } 4\end{array}$ & AESCRJ & $\begin{array}{l}\text { Intendente } \\
\text { Magalhães }\end{array}$ & Terça & 8 & $\begin{array}{l}\text { Carandiru } 2 \text { e es- } \\
\text { paços próximos } \\
\text { das quadras }\end{array}$ & $\begin{array}{l}\text { Sexta } \\
\text { divisão }\end{array}$ \\
\hline $\begin{array}{l}\text { Grupo de } \\
\text { Avaliação }\end{array}$ & AESCRJ & $\begin{array}{l}\text { Intendente } \\
\text { Magalhães }\end{array}$ & Terça & 2 & $\begin{array}{l}\text { Carandiru e espa- } \\
\text { ços próximos das } \\
\text { quadras }\end{array}$ & $\begin{array}{l}\text { Sétima di- } \\
\text { visão } \\
\text { - esporádica }\end{array}$ \\
\hline
\end{tabular}


Partiremos, portanto, da classificação do Carnaval 2010, utilizada pelas escolas, que as divide em grupos de acordo com normas estabelecidas pelo regulamento de cada entidade que congrega as escolas de samba. A seguir pode-se observar a entidade à qual cada um desses grupos está ligado. Outro dado importante para acompanharmos a montagem dessa estrutura hierárquico-competitiva é o local de desfile dos grupos, seguido dos dias de desfile de cada um deles. Apresentamos, ainda, o número de escolas participantes dos desfiles em cada um dos grupos, os locais de preparação das alegorias da maior parte das escolas do grupo e, finalmente, uma classificação neutra com o objetivo de aproximar esse conjunto de dados da realidade de um leitor não muito familiarizado com os desfiles e com esse sistema. $^{2}$

Vamos, ao longo do texto, nos aprofundar nesse complexo sistema, com vistas a naturalizá-lo e traduzi-lo para o leitor.

\section{OS GRUPOS E SUAS ENTIDADES ORGANIZADORAS: COMO FUNCIONA A HIERARQUIA COMPETITIVA}

Em 2010 o desfile de escolas de samba, na cidade do Rio de Janeiro, estava separado em sete divisões ou graus hierárquicos, as maiores escolas ocupando o topo, e aquelas que ainda não eram oficialmente classificadas como escolas, o grau mais baixo. ${ }^{3}$ Paralelamente a esse mundo das escolas de samba, outra forma carnavalesca - os blocos de enredo - convive com esse sistema em constante interseção, pois a cada ano há blocos que viram escolas e escolas que viram blocos. ${ }^{4}$

O regime hierárquico que organiza a competição anual se mantém ao longo da história de vida das escolas na cidade. No entanto, essas divisões - número de escolas em cada uma delas, sua denominação e até mesmo o número dessas divisões - se alteram muito. Na história das escolas de samba, vemos que são recorrentes as mudanças na nomenclatura da divisão hierárquica da competição. Por exemplo, nos primeiros anos do desfile havia apenas um único grupo a disputar entre si o campeonato carnavalesco. Esse grupo, que chegou a abrigar 35 escolas em 1948, já foi chamado de Grupo 1 (de 1952 a 1978 e de 1987 a 1990) e Grupo 1-A (de 1979 a 1987). ${ }^{5}$
1 Nesse grupo apenas a Renascer de Jacarepaguá preparava suas alegorias no Carandiru.

2 A classificação neutra obedece a uma ordem que relaciona cada grupo a uma divisão, pois é o que são de fato; e os organiza hierarquicamente seguindo classificação ordinal descendente, em que a primeira divisão é o topo da hierarquia, e a sétima divisão, a base.

3 A primeira vez que se adotou um desfile de avaliação antes da filiação de novas escolas de samba ao grau hierárquico mais baixo foi em 1996. Esse sistema vigora desde então.

4 Além dos blocos de enredo existem blocos de embalo e outras formas caranavalescas espalhadas pela cidade inteira. Os blocos de enredo, entretanto, têm estrutura organizacional mais parecida com a das escolas de samba, até por participar de competição entre eles, o que não acontece com os blocos de embalo.

5 Bastante esclarecedor a respeito de histórico completo sobre a questão da nomenclatura dos grupos é o quadro elaborado por Araújo (2009) no artigo Vida e morte nas pequenas escolas de samba. 
Interessa-nos aqui compreender a montagem desse regime hierárquico que preside o sistema festivo competitivo, e, para tanto, são relevantes as informações sobre os processos associativos desenvolvidos no meio das escolas de samba.

\section{AS ORGANIZAÇÕES}

A primeira organização representativa das escolas de samba de que se tem notícia foi a União das Escolas de Samba - UES, já em 1934. No ano seguinte foi oficializado o reconhecimento dos desfiles das escolas de samba como atração turística da cidade (CABRAL, 1996). Assim, já no Carnaval de 1935, temos o primeiro desfile organizado pela UES, subvencionado pela Prefeitura do Rio de Janeiro.

Surgiram, em 1947, duas outras organizações: a Federação das Escolas de Samba (reconhecida pelos órgãos oficiais) e a União Geral das Escolas de Samba (ligada ao Partido Comunista Brasileiro); com a criação das duas novas entidades, a UES foi dissolvida (FERREIRA, 2004).

Então, em 1952, as duas entidades se fundiram formando a Associação das Escolas de Samba do Carnaval do Rio de Janeiro - AESCRJ, que passou a administrar os desfiles e a congregar todas as escolas da cidade do Rio de Janeiro. A AESCRJ permaneceu à

6 Já em 1984, com a inauguração do sambódromo, a Liesa torna-se importante articuladora dos interesses de controladores do jogo do bicho e administradora dos mais diferentes interesses referentes às escolas de samba, como a comercialização de discos e a distribuição de direitos entre elas. $O$ sistema de venda de ingressos também é, desde então, controlado pela Liesa e, nos últimos anos, os quase 60 mil ingressos, cujos preços variam de dez a cinco mil reais, têm esgotado em menos de uma semana. frente do carnaval carioca até 1984, quando um grupo de grandes escolas, até então pertencentes à Associação fundou a Liga Independente das Escolas de Samba - Liesa (CAVALCANTI, 2006, p. 43). Assim, a AESCRJ passou a administrar apenas os demais grupos do carnaval carioca. A Liesa, desde então, assumiu o controle da organização do desfile das escolas de samba do Grupo Especial, ${ }^{6}$ a primeira divisão do carnaval carioca.

Em 2008, um grupo de sete escolas pertencentes ao Grupo de Acesso A, a segunda divisão do carnaval carioca, fundou a Liga das Escolas do Grupo de Acesso - Lesga, que passou a coordenar todo o processo de organização do desfile do Grupo de Acesso A. Assim, a AESCRJ deteve a organização apenas dos quatro grupos inferiores a esse. Após o Carnaval de 2010 as escolas da terceira divisão saíram da AESCRJ e juntaram-se às escolas da segunda divisão na Lesga.

Sumarizamos essa estrutura competitiva do Carnaval 2010 de acordo com alguns pontos que facilitarão a apresentação de nossos dados. Seguem-se os aspectos da organização das escolas de samba que distinguem os graus hierárquicos entre si.

Inicialmente temos o nome dos grupos e da associação a que pertence. Essa definição é de suma importância, pois cada um deles tem regulamento próprio ligado à realização de seus desfiles. Simultaneamente, de acordo com os grupos, há diferentes localização e data dos desfiles. Temos ainda formas e valores de subsídio de acordo com o 
nível hierárquico ocupado pela escola, e, consequentemente, a cobrança e o preço dos ingressos dependerão de outro aspecto importante: a atenção e a cobertura da mídia.

A quantidade de alegorias e componentes no desfile, apesar de ser outro aspecto regido por regulamento, pode variar de escola para escola, de acordo com sua posição no quadro competitivo e de questões conjunturais não necessariamente ligadas à competição (como é o caso de afinidade dos interessados em desfilar na escola e com sua administração, facilidade de acesso às quadras ou aos intermediários que vendem fantasias, além da visibilidade da escola no cotidiano da metrópole).

$E$, finalmente, uma diferença recente, mas não menos importante, que é o local de preparação do desfile (infraestrutura, proximidade do local do desfile).

Interessante percebermos, através da complexa estrutura apresentada, a forma com que são encaradas pelos sambistas as categorias "subir" e "descer". Muitas vezes a trajetória de uma escola traz necessariamente referências à velocidade de sua ascensão ou queda. A ascensão dentro da hierarquia, ou a "subida" de grupo, é valorizada dentro de um projeto de sucesso, segundo o qual as menores escolas devem ao menos alcançar o Grupo Especial. Assim, uma escola que hoje ocupa um dos grupos que desfilam na Intendente é lembrada por sua passagem pelo Grupo Especial. Simultaneamente, uma escola que tenha passado rapidamente por todos os grupos da Intendente Magalhães é encarada com respeito na chegada ao Grupo de Acesso A. A dificuldade em se manter no Grupo Especial, no entanto, valoriza ainda mais a passagem do Grupo de Acesso A para o Grupo Especial. Este é o grande objetivo de toda agremiação carnavalesca no Rio de Janeiro: tornar-se uma escola do Grupo Especial. Composto pelas maiores e consideradas oficialmente as melhores escolas do carnaval carioca, esse grupo desfila no domingo e na segunda-feira de carnaval, no sambódromo. Trata-se da mais alta posição hierárquica na estrutura competitiva do carnaval carioca e é valorizada pela dificuldade em conseguir fazer parte do seleto grupo. Com o crescimento da festa e o aumento no número de escolas, chegar a tal grupo tornou-se tarefa cada vez mais difícil.

Como aponta Araújo (2008), na outra ponta da estrutura temos os chamados, pelos sambistas, "Grupos de Acesso" assim reunidos em um conjunto que os coloca em oposição com o "sucesso" e "plenitude" que significa o Grupo Especial ou a primeira divisão do carnaval carioca. Desse modo, os "Acessos" traduzem "uma falta, uma necessidade um esforço para conquista" (ARAÚJO; 2008, p. 71); mais do que isso, é um estado transitório, ou se quisermos avançar ainda mais na questão, um estado liminar no sentido ritual (TURNER, 1978). Esse "acesso", porém, pode ser desdobrado em muitos "acessos". Ainda que o objetivo de toda escola seja alcançar o patamar mais alto de todas as escolas no Grupo Especial, muitas se contentam com metas mais próximas de sua realidade e, portanto, algumas escolas nascem sonhando em ao menos chegar a desfilar no sambódromo. Outras, abatidas pela crise, sonham em se reerguer e voltar ao sambódromo. Assim, chegamos a um segundo estado que pode ser um primeiro objetivo de todas as escolas: alcançar ou ao menos manter-se por um tempo desfilando na terceira divisão do carnaval carioca, o grupo Rio de Janeiro 1. 
"Subir" e "descer" são palavras marcantes para descrever a trajetória de uma escola. Podemos dizer, portanto, que faz parte do universo ritual das escolas de samba "subir" ou "descer", e a definição de quantas sobem ou descem é de profunda importância

7 Tal fato tem restringido cada vez mais a permanência no Grupo Especial da escola que ascendeu do Grupo de Acesso A. Desde que tal mudança no regulamento foi efetuada (em 2002) apenas a Vila Isabel em 2005 e a União da Ilha no carnaval de 2010 permaneceram no Grupo Especial.

8 No artigo citado, Cavalcanti calcula em mais de 67 milhões os recursos movimentados pela Liesa. Os dados foram coletados a partir do relatório da CPI do Carnaval em 2008 na Assembleia Legislativa do Estado do Rio de Janeiro.

9 Ver em Araújo, 2008 os valores de subvenção $e$ orçamentos dos diferentes grupos do carnaval carioca.

10 Os quesitos são: Bateria, Samba-enredo, Harmonia, Evolução, Enredo, Conjunto, Alegorias e Adereços, Fantasias, Comissão de Frente, e Mestre-Sala e PortaBandeira. para o desenrolar da festa. É assim que podemos encontrar explicação para a dinâmica da criação ou extinção e até mesmo do processo de crise ou ressurgimento de uma escola de samba.

Atualmente, há cinco segmentos abaixo do Grupo Especial, e as regras atuais restringiram a "subida" para esse grupo a apenas uma escola por ano. ${ }^{7}$ Aqui, estima-se que um desfile produzido nesse grupo seja orçado em até cinco milhões de reais (ARAÚJO: 2008, p. 59). Por ser transmitido ao mundo inteiro pela Rede Globo de Televisão, muitas pessoas querem desfilar nessas escolas, e seus ensaios e fantasias, que garantem lugar entre os desfilantes, são disputadíssimos. A administração desse grupo, como vimos, fica por conta da Liesa, controlada por notórios contraventores ligados ao jogo do bicho e ao mecenato das maiores escolas (CAVALCANTI, 2009). ${ }^{8}$

Logo abaixo, na estrutura hierárquico-competitiva das escolas de samba, vem o que chamaremos de Grupo de Acesso A ou a segunda divisão das escolas de samba, cujo desfile acontece no sambódromo, no sábado de carnaval (ARAÚJO, 2008). No Carnaval de 2009, após pedirem desfiliação da AESCRJ, as escolas desse grupo fundaram outra associação, a Liga das Escolas de Samba do Grupo de Acesso - Lesga, que administra atualmente os desfiles.

No Grupo de Acesso A, as subvenções são bem menores do que no Grupo Especial, e o teto de gastos da escola mais rica já foi avaliado em um milhão de reais. ${ }^{9}$ Os preços dos ingressos são bem inferiores aos da primeira divisão e custavam, em 2009, de dez a mil reais. A venda de ingressos não tem tanto apelo quanto a dos desfiles da primeira divisão, embora a cada ano possa ser observado significativo crescimento. A emissora responsável pela transmissão do desfile varia de ano para ano, e no Carnaval de 2009 foi fruto de produção independente da Lesga, que comprou espaço na CNT. Muitas escolas que já estiveram na primeira divisão das escolas de samba do Rio de Janeiro hoje compõem o Grupo de Acesso, do qual apenas três nunca estiveram no Grupo Especial: a Inocentes de Belford Roxo, a Renascer de Jacarepaguá e a Acadêmicos do Cubango. Assim, como acontece no Grupo Especial, ${ }^{10}$ as escolas são julgadas em dez quesitos, com quatro jurados para cada quesito. 
Existe grande diferença organizacional e de vários outros aspectos entre os dois primeiros graus hierárquicos desse sistema competitivo - o Grupo Especial e o Grupo de Acesso A - e os demais grupos.

Abaixo do Grupo de Acesso A está o Grupo Rio de Janeiro 1 , denominação que adotaremos no presente trabalho. ${ }^{11}$ Disputaram o título desse grupo, no Carnaval de 2010, 12 escolas. Entre as diferenças sinalizadas está o fato de seu desfile não ser transmitido pela televisão e de poucas emissoras de rádio do Rio de Janeiro o acompanharem na íntegra. Os ingressos de arquibancada são distribuídos, e, nos últimos anos, em face do exíguo público interessado nos ingressos antecipadamente, a entrada nas arquibancadas tem sido liberada na hora do desfile, que acontece na terça-feira de carnaval e se estende até a manhã da quarta-feira de cinzas. Apesar de os quesitos serem iguais aos do Grupo Especial e do Grupo de Acesso A, há apenas três jurados por quesito, e a menor nota em cada um é descartada. Outra grande diferença é em relação ao tempo máximo de desfile

11 Essa denominação passou a ser adotada a partir da cisão criada com as escolas pertencentes à Lesga em relação à AESCRJ. Antes da cisão o grupo era conhecido como Grupo de Acesso $B$ desde 2000. Antes disso já havia sido conhecido como Grupo B (de 1996 a 2000), Grupo de Acesso 2 (1995), Grupo 2 (de 1987 a 1994), Grupo 2-A (de 1979 a 1986) e Grupo 3 (de 1960 a 1978). de cada escola. Enquanto na primeira divisão cada escola tem 82 minutos para percorrer toda a pista de desfile e na segunda divisão, 60 minutos, na terceira divisão cada escola deve apresentar-se em 50 minutos.

Abaixo dessa divisão estão os Grupos Rio de Janeiro 2, 3 e 4, cujos desfiles acontecem na Estrada Intendente Magalhães, em Campinho. A criação desses grupos atendeu à necessidade de subdivisões que abarcassem número cada vez maior de escolas.

O desfile do Grupo Rio de Janeiro 2, ou a quarta divisão, acontece no domingo de carnaval, simultâneo ao primeiro dia de desfiles das grandes escolas na Sapucaí. Nesse grupo, são 14 escolas desfilando e, no Carnaval 2010, três delas ascenderiam à terceira divisão, obtendo assim o direito de desfilar no sambódromo no ano seguinte, e as três últimas seriam rebaixadas à quinta divisão. Há grande diferença também no orçamento dessas escolas em relação aos grupos que desfilam no sambódromo - o desfile da Acadêmicos do Dendê em 2009, no Grupo Rio de Janeiro 2, foi orçado em 50 mil reais. Os desfiles do Grupo Rio de Janeiro 2 só 12 No Carnaval 2009 apesão transmitidos por duas rádios: a rádio comunitária da região de Campinho e Vila Valqueire e a rádio 1440AM; alguns poucos sites também os acompanham. ${ }^{12}$ Esse grupo já foi conhecido como Grupo 2-B, até 1983, depois como Grupo 4, até 1990, quando passou a chamar-se Grupo 3 e, finalmente, antes da denas os sites OBatuque. com, Galeria do Samba e Esquina do Samba, além do troféu samba-net, com premiação voltada para os grupos inferiores. nominação atual, Grupo de Acesso C, desde 1996.

Participaram do Grupo Rio de Janeiro 3 em 201015 escolas. O grupo desfila na segunda-feira de carnaval. A média orçamentária de uma escola desse grupo em relação às do Grupo Rio de Janeiro 2 é praticamente igual. Como acontece no grupo já descrito, três escolas sobem, e três são rebaixadas ao Grupo Rio de Janeiro 4. A cobertura dos des- 


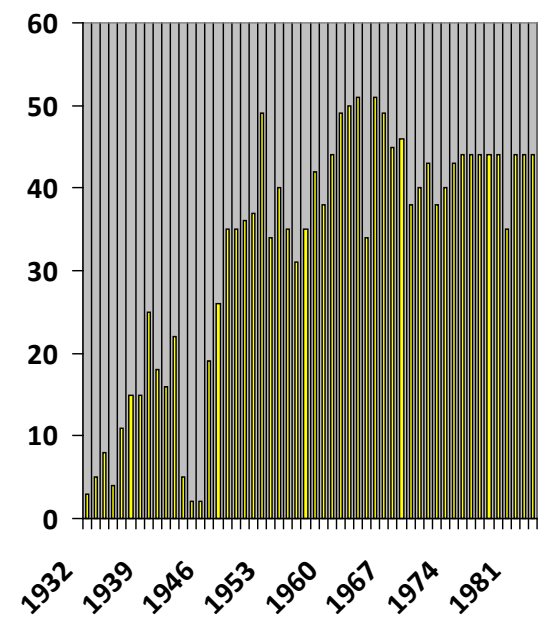

Tabela 1: Número de escolas desfilantes antes da inauguração do sambódromo

No. De escolas

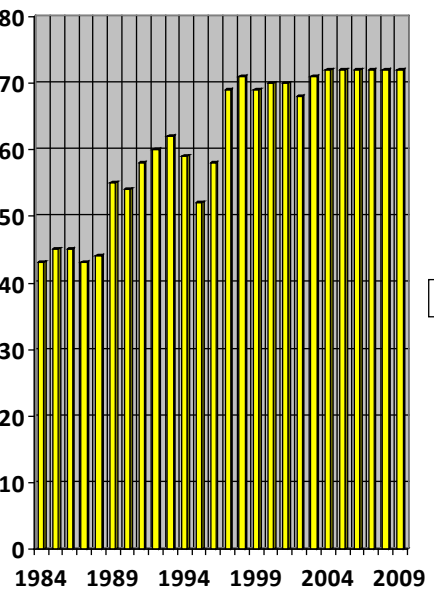

files foi realizada pelos mesmos sites e rádios que participaram da cobertura do Grupo Rio de Janeiro 2.

O último grupo na hierarquia competitiva das escolas de samba é o Grupo Rio de Janeiro 4, no qual desfilam oito escolas. A última colocada deixa de desfilar entre as escolas de samba e fica obrigatoriamente licenciada da AESCRJ por um ano. A escola licenciada só pode voltar a desfilar novamente após quitar suas dívidas e provar o cumprimento dos requisitos legais para uma agremiação recreativa. Os recursos nesse grupo são muito mais reduzidos, a começar pela estrutura mínima de desfile, muito menor, cabendo apenas um carro alegórico por escola, no máximo. Tem-se, aqui, situação simbolicamente inversa à do Grupo Especial, pois se trata do último grupo na hierarquia competitiva. Nele são encenados tanto o surgimento como a decadência ou desaparecimento de escolas. Nesse desfile a atenção causada é ainda menor que nos demais. Apesar do bom público presente, garantido especialmente pelos moradores da região, só a rádio comunitária transmitiu o desfile, que mereceu a cobertura apenas dos sites OBatuque.com e Esquina do Samba.

A situação de liminar é evidenciada de fato no Grupo de Avaliação. Os desfiles acontecem logo após as apresentações das escolas da sexta divisão, mas o aparecimento desse grupo é esporádico, e só quando alguma escola tem o pedido de filiação submetido à avaliação pela AESCRJ o desfile, de caráter não competitivo, é realizado. Nesta situação cada escola é avaliada como "aprovada" ou "reprovada", de acordo com apresentação de itens obrigatórios definidos em regulamento ocasional da AESCRJ. 


\section{NÚMERO DE ESCOLAS E DE COMPONENTES}

O número de escolas pode ser tema de interessante investigação e revelador, até certo ponto, da importância e relevância das escolas de samba dentro das redes de relações na cidade. Assim, é possível enxergar grande diferença nessa estrutura ritual-competitiva para aquela descrita por Maria Isaura Pereira de Queiroz (1999, p. 75) em seu artigo Escolas de Samba do Rio de Janeiro ou a domesticação da massa urbana, constante no livro Carnaval brasileiro: o vivido e o mito, referente ao Carnaval de 1980. Naquela época, a estrutura das escolas de samba do Rio de Janeiro era controlada única e exclusivamente pela AESCRJ. Os desfiles aconteciam todos no Centro da cidade, e, quando as escolas desfilavam próximo de suas comunidades, era por iniciativa própria. A hierarquia competitiva entre as agremiações era muito mais simples, até pelo fato de serem apenas 44 escolas, divididas em três grupos. Podemos observar o avanço e a progressão no número das escolas de samba na cidade através da análise dos quadros de escolas participantes dos desfiles oficiais desde 1932 (Tabelas 1 e 2)

Percebemos que atualmente as escolas atingem o grau máximo de expansão no número de agremiações não apenas na cidade do Rio de Janeiro, mas também em cidades da região metropolitana constantes nesses números. A expansão ou recrudescimento dentro de tal quadro obedece a situações conjunturais, mais ou menos estruturadas, mas que atendem, por sua vez, a uma lógica interna e externa à organização dos desfiles, por exemplo, as vontades dos organizadores ou questões políticas. Algo que chama atenção, por exemplo, é a relação entre a criação de novas entidades ou grupos e a ampliação no número de escolas, que pode ser inferida quando confrontamos o quadro acima com a relação do item anterior (criação da AESCRJ em 1952 e aumento significativo no número de escolas filiadas). Porém, a criação de escolas de samba se opera de maneira muito particular em diferentes situações e contextos. O que percebemos é a permanência, ou ao menos certa regularidade no número de componentes, com respeito às grandes escolas senão a todas. Na década de 1980, por exemplo, havia em média quatro mil componentes em cada uma das grandes escolas (QUEIROZ, 1999). Podemos também observar um processo de retração entre 1976 e 1980. Logo a seguir, com a democratização do país, há um novo processo de expansão, identificado a partir de 1989, até chegar ao atual número de 72 escolas, a partir de 2004, que se manteve estável até o Carnaval 2010.

Destaca-se, portanto, nesse processo a contínua expansão das escolas de samba pela cidade. É importante ressaltar essa expansão especialmente em um contexto de ataques à vivacidade do fenômeno das escolas de samba por parte de puristas em desacordo com os rumos tomados por essa manifestação. Explica-se essa expansão pela expansão concomitante da metrópole e incorporação contínua de agremiações de fora do município do Rio de Janeiro. A contínua e acelerada incorporação especialmente no início da década de 1990 também justifica o aumento da complexidade na hierarquia competitiva.

No Grupo Especial, em que estão as maiores escolas, cada uma desfila com oito alegorias e aproximadamente quatro mil componentes; no Grupo de Acesso A, com cinco 
carros alegóricos e três mil componentes; no Grupo Rio de Janeiro 1, com quatro carros e até 1.500 componentes; no grupo Rio de Janeiro 2, com três carros alegóricos e cerca de mil componentes, número mínimo exigido pelo regulamento que rege esse grupo.

No Grupo Rio de Janeiro 3, apesar do número mínimo de 800 componentes determinado por regulamento, segundo Araújo (2008, p. 144), poucas escolas reúnem tantos desfilantes, trazendo em geral 600 componentes e dois carros. Isso também ocorre com o Grupo Rio de Janeiro 4, cujas escolas se apresentam com um carro e cerca de 400 componentes, quando o número exigido pelo regulamento é de 500 componentes.

No caso dos três últimos grupos citados, fica evidente que há tolerância por parte da AESCRJ em relação ao número mínimo de componentes exigidos pelo regulamento. Há ainda distinção interessante na natureza desses desfilantes em relação aos desfiles do Grupo Especial. No caso dos demais grupos, boa parte dos componentes se reúne em escala gradativa, com relação aos grupos, desfilando em mais de uma escola a cada ano. Essa prática é recorrente há um bom tempo, identificada ainda no período em que as pequenas escolas desfilavam na Avenida Rio Branco, enquanto as grandes desfilavam na Sapucaí. Assim, muitos componentes saíam de um desfile na Rio Branco encaminhando-se para a Sapucaí, dada a proximidade das duas pistas de desfile, localizadas no Centro do Rio de Janeiro.

\section{DIAS E LOCAIS DE DESFILE}

No plano da cidade, com suas múltiplas formas de expressão carnavalesca, incluindo blocos e coretos, diversos eventos acontecem. No entanto, apesar de a cidade viver dias movimentados, nos fixaremos apenas nos espaços que são ou foram de alguma forma utilizados pelas escolas em seus desfiles, o "circuito das escolas de samba". Para tanto, utilizaremos o conceito de "circuito", elaborado por Magnani (2007, p. 34).

O primeiro local de apresentação das escolas de sam-

$13 \mathrm{Em} O$ livro de ouro do carnaval brasileiro, Felipe Ferreira (2004, p. 360) nos passa um panorama da peregrinação das escolas pelo Centro da cidade até chegar a um local definitivo de apresentação. ba cariocas foi a Praça XI (CABRAL, 1996; FERREIRA, 2004 e CAVALCANTI, 2006), até hoje lembrada com nostalgia pelos sambistas mais antigos. ${ }^{13}$

Depois disso o desfile ainda retornaria para a Avenida Presidente Vargas, dessa vez já consagrado como a grande atração do calendário carnavalesco carioca, chegando, em 1979, na Avenida Marquês de Sapucaí, que se tornaria, em 1984, palco definitivo das escolas de samba (FERREIRA, 2004, p. 372). Em

1983 o então governador Leonel Brizola anuncia a intenção de construir uma passarela definitiva para as escolas de samba, o que acabaria com o monta e desmonta das estruturas tubulares na pista de desfiles (CAVALCANTI, 2006, p.43).

Idealizada por Oscar Niemayer, a Passarela do Samba, que logo a seguir seria conhecida como sambódromo, foi construída em tempo recorde: apenas 120 dias separaram a aprovação do projeto e o término da construção da passarela (CAVALCANTI, 
2006). A Passarela do Samba representou efetivamente um marco no processo de espetacularização dos desfiles. Logo a seguir, impulsionados pelo novo espaço, as grandes escolas se reuniram para fundar a Liesa, em 1985. Assim, com capacidade para mais de 60 mil pessoas, o sambódromo, oficialmente batizado de Passarela do Samba Darcy Ribeiro, mas ainda hoje conhecido como "Sapucaí" ou "avenida", é o espaço mais valorizado do carnaval brasileiro.

Como vimos, na década de 1950 o reconhecimento das escolas de samba na cidade do Rio de Janeiro, bem como sua posterior valorização, representou também importante estímulo para a criação de inúmeras agremiações nos mais diferentes pontos da cidade. Quando da inauguração do sambódromo, havia 43 escolas, que não dividiam o espaço de desfiles. No primeiro ano de Passarela do Samba, apenas as escolas da primeira e da segunda divisão do carnaval carioca ali desfilaram; as demais agremiações se apresentaram na Avenida Rio Branco. As pequenas escolas permaneceram nesse espaço no Centro do Rio de Janeiro até 1998, quando os desfiles da quinta e sexta divisões foram transferidos para a Avenida Cardoso de Morais, no bairro de Bonsucesso, subúrbio da cidade. A intenção era experimentar espaços diferentes, desafogando a Rio Branco, que as escolas dividiam com blocos de enredo e de empolgação. Como os blocos atravessavam a Avenida Rio Branco antes e durante os desfiles das escolas, estas geralmente se queixavam de problemas de ordem organizacional. $O$ desfile da quarta divisão permaneceu no local.

As escolas continuaram se apresentando em Bonsucesso até 2002, quando as quinta e sexta divisões passaram a desfilar na Estrada Intendente Magalhães, em Campinho, pequeno bairro entre Madureira, Vila Valqueire e Jacarepaguá, bem distante do Centro do Rio. As escolas reclamavam na época de represálias de facções rivais no percurso para Bonsucesso. Essa questão pode ser problematizada, no entanto. Tomemos, por exemplo, depoimentos de componentes da Acadêmicos do Dendê que desfilaram em todas as passarelas aqui citadas:

O grande problema de Bonsucesso era a curva na pista de desfile. Lá teve tiroteio na dispersão, mas foi só um ano. E aquele negócio era briga de vagabundo, de malandro e não tinha como se envolver. Quem não é disso não se envolve (...). Além do que a Intendente não é tão segura assim para desfilar. Lá é área do Comando Vermelho, o Dendê é área do Terceiro Comando (...) Não sei dessa milícia lá não (...) E também tem o percurso do barracão à avenida, que é muito perigoso. Os carros passam por várias favelas de facções diferentes na Linha Amarela (componente do Dendê; 30.10.2008).

Um dos interlocutores me dizia que, para a escola, o melhor local seria a Avenida Rio Branco, no Centro do Rio. Segundo apontaram alguns dos componentes do Dendê, o grande problema da Avenida Rio Branco, que ainda abrigava as escolas do Grupo C na época, era o total descaso dos organizadores com a estrutura da passarela e a falta de suporte dado pela prefeitura para a realização dos desfiles. Um dos entusiastas dos desfiles, que ainda os acompanha na Intendente Magalhães, conta como eles eram na Rio Branco e em Bonsucesso, e os compara com os atualmente realizados na Intendente Magalhães: 
14 O horário de realização dos desfiles pode ser alterado de ano para ano de acordo com o número de escolas participantes e mudanças nos regulamentos do desfile.

15 O horário de desfiles é ponto de preocupação constante entre as escolas de samba. A determinação de um horário para início dificilmente é respeitada, e ocorrem atrasos corriqueiros. Na história dos desfiles, entretanto, diversos problemas aconteceram em relação a tal tema. Houve inclusive anos em que as apresentações das grandes escolas começavam com o sol se pondo e terminavam quase no meio do dia seguinte. Uma das formas mais eficientes encontradas pelos organizadores de coibir que os desfiles se estendessem por muito tempo foi a delimitação regulamentar do tempo de apresentação das escolas de samba. Atualmente este tempo varia de grupo para grupo. No Grupo Especial outra forma de dinamizar a apresentação das escolas foi através da divisão da apresentação das escolas em dois dias de desfiles, assim seis se apresentam no primeiro dia e mais seis no segundo. $A$ primeira vez em que tal divisão aconteceu no carnaval carioca foi no ano de inauguração do sambódromo, em 1984.
Era uma bagunça na Rio Branco. Além de muito mal iluminados, os desfiles começavam com atrasos enormes. Quem causava os atrasos eram os blocos que atravessavam a pista antes e durante os desfiles. Desfile lá começava às $21 \mathrm{~h}$, quando o combinado era $19 \mathrm{~h}$, e ia atrasando conforme as escolas passavam. Nessa época (por volta de 2002) tinha muito pouca gente assistindo na arquibancada por causa dos assaltos (pesquisador; 15.6.2008).

Assim, em 2005, a quarta divisão também passa a desfilar na Estrada Intendente Magalhães. Lá, arquibancadas tubulares e cabines para jurados e para imprensa são montadas em uma parte da via. O início dos desfiles é marcado logo após a Praça dos Lavradores e termina depois da Rua Carlos Xavier. A concentração das escolas ocorre no trecho inicial da via até seu entroncamento com a Rua Domingues Lopes. Atualmente, um dos principais problemas na pista de desfiles da Intendente Magalhães é a concentração, pois nesse local os carros alegóricos das escolas dividem espaço com o trânsito comum até a chegada ao trecho interditado.

Oficialmente, o calendário de desfiles de escolas de samba na cidade do Rio de Janeiro é aberto na sexta-feira, com a apresentação das escolas de samba mirins, na Avenida Marquês de Sapucaí, começando às $17 \mathrm{~h}$ e terminando por volta da meianoite.

No sábado de carnaval é a vez das escolas de samba do Grupo de Acesso A, também na Marquês de Sapucaí, em geral ${ }^{14}$ a partir das $20 \mathrm{~h} .{ }^{15}$ Nos últimos anos, esses desfiles têm terminado às seis ou sete horas da manhã de domingo.

No domingo de carnaval começam os desfiles do Grupo Especial no sambódromo, sendo atualmente de seis escolas no horário das $21 \mathrm{~h}$ às seis horas da manhã de segunda-feira. Esse costuma ser o dia menos valorizado, e a escola que ascendeu do Grupo de Acesso A abre ${ }^{16}$ o desfile - desde que o sambódromo foi inaugurado a maior parte das campeãs desfilou na noite de segunda-feira, portanto a mais valorizada.

Simultaneamente, acontecem na Intendente Magalhães os desfiles das escolas de samba das quarta e quinta divisões: no domingo, as do Grupo Rio de Janeiro 2, a quarta divisão, a partir das 19h, com término por volta das seis horas da manhã; na segunda-feira, as do Grupo Rio de Janeiro 3, a quinta divisão, com início também às $19 \mathrm{~h}$ e término por volta das cinco horas da manhã. 
Na terça-feira de carnaval desfilam no sambódromo as escolas do Grupo Rio de Janeiro 1, a terceira divisão, apesar da indefinição, o que, aliás, tem sido motivo de inúmeros debates. ${ }^{17}$ Criado em 1998, esse grupo desfilava na sexta-feira, quando as escolas mirins desfilavam na quinta-feira. Em 1998, o caos que se instalou no trânsito do Centro do Rio de Janeiro nesse dia foi atribuído à movimentação dos carros desse grupo, e no ano seguinte o dia de desfiles foi modificado, por solicitação da prefeitura. Todos os anos, porém, as escolas desse grupo reivindicam a volta para a sexta-feira, argumentando que a terça-feira é muito esvaziada e que é prejudicial o fato de os desfiles acabarem na manhã da quarta-feira de cinzas, quando muitos dos desfilantes já retomam a rotina de trabalho - os desfiles de terça-feira no sambódromo começam às $19 \mathrm{~h}$ e terminam por volta das sete horas da manhã.

Também na terça-feira de carnaval, na Intendente Magalhães acontecem os desfiles do Grupo Rio de Janeiro 4, a sexta divisão, que começam às 20h. A discussão em torno desse dia de desfiles tem natureza diferente. Como a AESCRJ está com a maior parte de seu quadro mobilizado para os desfiles de terça-feira no sambódromo, alguns defendem a extinção do grupo (ARAÚJO, 2008, p. 144).

\section{LOCAIS DE PREPARAÇÃO DO DESFILE}

O formato de preparação das escolas para os desfiles que vigora atualmente só começou a se esboçar na década de 1960 (GUIMARÃES, 2004). Até então as escolas utilizavam suas próprias quadras ou espaços próximos a elas. O primeiro espaço compartilhado de convívio entre as escolas dos mais diversos grupos na preparação para o carnaval foi o antigo Pavilhão de São Cristóvão, onde hoje funciona o Centro de Tradições Nordestinas Luiz Gonzaga. Ali várias escolas permaneceram até os anos 90 .

Outras escolas ocupavam galpões abandonados da Docas S.A. onde permaneceram, em comum acordo, regularmente até 1996 (BARBIERI, 2008). Em 2005 uma parte dessas escolas, as pertencentes ao Grupo Especial, trocou esses galpões pela Cidade do Samba, um complexo de grandes espaços para a produção dos desfiles das escolas desse grupo que, além de oferecer mais conforto e estrutura às escolas, tornou-se filão turístico administrado pela Liesa. A estrutura considerada ideal pelos sambistas e a grandiosidade que permite a divisão das etapas no processo de produção das alegorias têm levado à substituição da denominação nativa "barracão" por "fábricas".
16 A ordem de desfiles é definida por sorteio, que obedece a uma série de parâmetros estabelecidos em regulamento de acordo com as posições das escolas no desfile do ano anterior. As únicas escolas que não participam do sorteio no regulamento atual do Grupo Especial são a campeã do Grupo de Acesso A no ano anterior (que abre os desfiles do primeiro dia) $e$ a penúltima colocada do ano anterior (que abre o segundo dia de desfiles). Ver Regulamento da Liesa em http://liesa.globo. com/2010/por/03-carnaval10/Regulamento\%20 Carnaval\%202010\%20 -\%20LIVRO.pdf.

17 Sobre a discussão do dia de desfiles do Grupo Rio de Janeiro 1 ver Associação: Grupo B quer voltar a desfilar na sextafeira no Carnaval 2010, publicada em www. sidneyrezende.com/ noticia/58028. 
Ainda persistem, porém, diferentes espaços de produção das alegorias, o que indica a disparidade dos diferentes níveis de competição das escolas de samba. Existem, por exemplo, as que ainda produzem seu carnaval em suas quadras, como a Unidos de Manguinhos e a Unidos de Vila Kennedy. Existem ainda aquelas que ocupam galpões na Zona Portuária. Muitos desses galpões pertenceram às escolas do Grupo Especial antes da transferência para a Cidade do Samba. A maior parte das escolas que não fazem parte do Grupo Especial produz seus carnavais em espaços compartilhados nos chamados Carandirus.

Paralelamente ao projeto de construção da Cidade do Samba, no final de 2004, as escolas menores procuraram organizar-se buscando abrigo para suas alegorias. Foi nesse momento que essas pequenas escolas encontraram abrigo em outro terreno da RFFSA que servia de oficina de trens, bem próximo da já desativada gare da Leopoldina. A quantidade de lixo e sucata abandonada no local e a estrutura bastante depreciada do prédio levaram aqueles que ocuparam o espaço a chamá-lo de Carandiru. Na época o filme de Hector Babenco baseado no livro Estação Carandiru (1999), do médico Dráuzio Varella, que narra suas experiências com a dura realidade do presídio, ainda fazia bastante sucesso. Simultaneamente, discutia-se a implosão do presídio que aconteceria em meados daquele ano. O paralelo entre a total decrepitude do presídio e do prédio da RFFSA logo foi traçado pelos ocupantes do espaço. Atualmente, dividem esse espaço cerca de 13 escolas, da segunda à quinta divisão, além de um bloco de enredo e uma escola mirim, que convivem, segundo seus ocupantes, com mau cheiro, acúmulo de lixo, condições de trabalho insalubres, insegurança e constante risco de incêndio.

Essa ocupação repercutiu bastante na mídia nessa época, pois o governo resistia em ceder a área às escolas. Para tanto, contou muito a influência de alguns dirigentes, como Zezinho Orelha, presidente da União do Parque Curicica, antigo policial ferroviário e conhecedor do terreno. Quando ia a programas de rádio reivindicar sua permanência, geralmente tratava o terreno em questão pelo apelido de Carandiru, que acabou "pegando" entre as pessoas envolvidas com a produção do carnaval, o "mundo do samba".

Com a transferência dos desfiles para a Estrada Intendente Magalhães, em 1998, outro grupo de escolas procurou espaço próximo à pista dos desfiles. Assim foi ocupado por um período um antigo galpão da Cobal de Jacarepaguá, que viria a ser destruído e transformado na Praça dos Lavradores. Com isso as escolas que lá se encontravam transferiram-se para outro espaço, um antigo depósito de bebidas da Antártica, na esquina das ruas Carlos Xavier e Henrique Braga, em Campinho, logo apelidado de Carandiru 2. As condições de ocupação desse espaço são parecidas com as do Carandiru da Zona Portuária, mas a grande vantagem é a proximidade desse espaço da pista de desfiles da Intendente Magalhães.

\section{CONCLUSÃO}

A estrutura ritual do carnaval carioca é tema importante de pesquisa, pois evidencia as múltiplas relações e posições ocupadas pelas escolas no processo ritual-com- 
petitivo dos desfiles. Essas posições são relevantes para o posicionamento e prestígio dos componentes das escolas e até mesmo a posição ocupada pelo local ao qual estão ligadas no contexto da metrópole.

As diferentes condições que cada escola tem nos diferentes grupos envolvem questões de sociabilidade e conflito que ultrapassam o campo festivo e transbordam nas relações cotidianas dos sambistas e sua forma de enxergar a cidade. Ser membro de uma pequena escola oferece assim desvantagens estruturais evidenciadas através da etnografia da hierarquia competitiva. A posição que esse membro ocupa em uma pequena escola, por exemplo, pode ser relativizada e ser relevante dependendo dos interesses em jogo. Mediadores desempenham papel importantíssimo também na circulação entre as diferentes posições hierárquicas assumidas pelas escolas em sua trajetória.

Importante observar que uma análise profunda dessas estrutura evidencia passagens significativas entre fases não explicitadas na estrutura ritual. A chegada à principal passarela de desfiles, a Marquês de Sapucaí, marca a entrada em fase completamente diferente para as escolas. Deixar de participar dos três grupos que ali desfilam também é sinal significativo de crise e decadência para seus componentes e rivais. A entrada no Grupo Especial, a primeira divisão, é o marco definitivo na trajetória desses grupos, que a valorizam ainda que dele não mais façam parte.

Temos, portanto, três significativas posições liminares nessa estrutura marcando passagens para a primeira e terceira divisões, e o grupo de avaliação; ou seja, a entrada no grupo das "grandes escolas" com sua visibilidade e estrutura desejadas pelos sambistas; a chegada à Marquês de Sapucaí; e a entrada no universo das escolas de samba.

\section{BIBLIOGRAFIA}

ARAÚJO, Eugênio. Valorizando a batucada: um estudo sobre as escolas de samba dos Grupos de Acesso C, D e E do Rio de Janeiro. São Luís: Tese de Doutoramento apresentada ao Programa de Artes Visuais da Escola de Belas Artes da Universidade Federal do Rio de Janeiro, 2008.

. Vida e morte nas pequenas escolas de samba: uma aproximação histórica e antropológica das escolas dos grupos de acesso C, D e E. In Textos Escolhidos de Cultura e Arte Populares, v.6, n.1, 2009, p.51-65.

BARBIERI, Ricardo. J. Cidade do Samba: do barracão de escola às fábricas de carnaval. In CAVALCANTI, M. L., GONÇALVES R. S. Carnaval em multiplos planos. Rio de Janeiro: Aeroplano, 2008, p. 125-144.

. Apuração no Terreirão. Textos Escolhidos de Cultura e Arte Populares, v. 6, n. 1. Rio de Janeiro, 2009, p. 173-182.

CABRAL, Sérgio. As escolas de samba do Rio de Janeiro. Rio de Janeiro: Lumiar, 1996.

CAVALCANTI, Maria. Laura. Festa e contravenção: os bicheiros no carnaval do Rio de Janeiro. In CAVALCANTI, M. L., GONÇALVES R. S. Carnaval em múltiplos planos. Rio de Janeiro: Aeroplano, 2009, p. 91-125.

. As alegorias no carnaval carioca: visualidade espetacular e narrativa ritual. In Textos Escolhidos de Cultura e Arte Populares, v.6. Rio de Janeiro, 2006, p. 17-27.

Carnaval carioca: dos bastidores ao desfile. Rio de Janeiro: UFRJ. 2006. 
DAMATTA, Roberto. O carnaval como rito de passagem. In Ensaios de Antropologia Estrutural. Petrópolis: Vozes, 1973.

FERREIRA, Felipe. O livro de ouro do carnaval brasileiro. Rio de Janeiro: Ediouro, 2004.

GUIMARÃES, Helenise. A Cidade do Samba: na paisagem da Gamboa as novas fábricas de sonhos para o carnaval carioca. Academia do Samba (www.academiadosamba.com. $\mathrm{br} / \mathrm{memoriasamba/artigos/artigo).} \mathrm{Rio} \mathrm{de} \mathrm{Janeiro,} 2004$.

MAGNANI, José. Guilherme. De perto e de dentro: notas para uma etnografia urbana. Revista Brasileira de Ciências Sociais. v. 17 n. 49, p. 11-29, 2002.

MAGNANI, José. Guilherme, MANTESE, B. Jovens na metrópole: etnografias dos circuitos de lazer, encontro e sociabilidade. São Paulo: Terceiro Nome, 2007.

MAUSS, Marcel. Ensaio sobre a dádiva. Lisboa: Edições 70, 2001.

QUEIROZ, Maria Isaura Pereira. Carnaval brasileiro: o vivido e o mito. São Paulo: Brasiliense, 1999.

SIMMEL, Georg. Questões fundamentais da sociologia. Rio de Janeiro: Jorge Zahar. 2006.

TURNER, Victor. O processo ritual. Petrópolis: Vozes. 1978.

Ricardo José de Oliveira Barbieri é mestre em antropologia pelo Programa de Pós-Graduação em Sociologia e Antropologia da UFRJ.

Artigo recebido em agosto de 2010 e aceito para publicação em outubro 2010. 